\title{
The research of technological characteristic of the vibrowave mechanical and chemical oxide coating formation
}

\author{
Vladimir Ivanov ${ }^{1}$, Anatoly Babichev ${ }^{1, *}$, and Nick Pogorelov ${ }^{1}$ \\ ${ }^{1}$ Don State Technical University, Rostov-on-Don, Russia
}

\begin{abstract}
The article presents experimental research devoted to the possibilities of usage for the vibrowave technology for the processing oxide coating on the details made of aluminum alloy. The technology of oxide coating formation is worked out in the process of vibrowave technology influence, that reflects the essence of complex impact of mechanical and chemical components on the formation go the top surface layer.
\end{abstract}

\section{Introduction}

Vibrowave processing allows to provide the effect of joint anergy influence, resulting from mechanical and chemical synthesis of the surface formation. Vibrowave processing provides alteration of physicochemical characteristic of the metal top layer, besides its activation. Taking into account its universal character, vibrowave equipment can be used not only for top layer formation but also finishing, scraping and hardening actions. that's of high importance due to decrease production net cost $[1,3]$.

Vibrowave processing can have the following parameters: regimes of main camera swaying; the time of details processing, density of the processed material; rough surface of the processed detail; capacity of the effective environment in the working camera; effective environment characteristic; the amount of oxid liquid in the working camera, liquor temperature [2].

The main aim of the given experimental research was the mastering of the most optimal highly-technological process of decorate surface inscription under vibrowave process system conditions.

The given research presupposes solution of the following tasks.

1. The selection of processing regimes and parameters, equipment, effective environment of the liquids in vibrowave abrasive finishing conditions .

2. The mastering of process coating inscription, for surface hardening of aluminum alloy and firmness definition.

\section{Research results}

The research to identify the degree of amplitude of swaying influence on the working camera on the thickness of oxide layer, they were carried out on the adenol aluminum samples (HB 28) and aluminium alloy
(HB 50), swaying frequency of the working camera $f=33,3$ Гц; processing duration, $\tau=30 \mathrm{~min}$, working material - polyethylene ball D 3-4 mm. Swaying amplitude was changing within the range, the most frequently used during the practice from 1 to $5 \mathrm{~mm}$. The amount of oxide liquid was calculated $30 \%$ from the bulk volume of the working camera, taking into account that it's filled with working material and details not more than for 0,8 of the total volume. The definition of the oxide layer thickness was carried out by the method of dropping [3].

The received data is presented in the table 1 , fig. 1 .

Table 1. The influence of that swaying amplitude on the thickness layer $(\mathrm{mcm})$

\begin{tabular}{|c|c|c|c|c|c|}
\hline \multirow{2}{*}{ Material } & \multicolumn{5}{|c|}{ Swaying amplitude, mm } \\
\cline { 2 - 6 } & 1 & 2 & 3 & 4 & 5 \\
\hline АДО & 5 & 5 & 4,9 & 4,7 & 4,4 \\
\hline АЛ9 & 4,2 & 4,2 & 4,1 & 3,9 & 3,5 \\
\hline
\end{tabular}

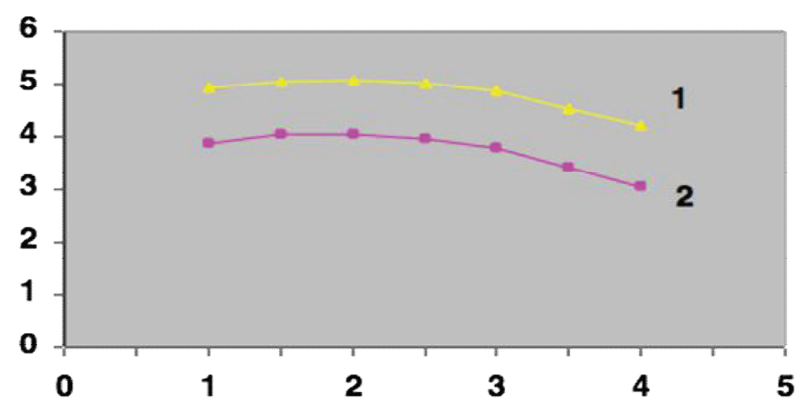

Fig. 1. The dependence of oxide layer thickness from the swaying amplitude of the working camera: 1 - aluminum; 2 - aluminum alloy

\footnotetext{
* Corresponding author: vibrotech@mail.ru
} 
As the researches have shown, the increase of swaying amplitude up to $A=2,5 \mathrm{~mm}$, it does not effect growth of oxide layer. With the swaying amplitude $3 \mathrm{~mm}$, however there is a certain decrease of oxide layer thickness, which does not cause the change of layer density $[4,5]$.

The research of the density for the vibrowave mechanical and chemical oxide layer (VMCOL) had its own specifics. The adenol alloy shields size 10 by 10 , thickness $2 \mathrm{~mm}$ were used as the research samples. Before the placing VMCOL, the sample surface were polished to get mirror effect $[6,7]$. Tridimensional SPM image of the micro print of the initial surface fig. 2. The indenter prints are quite visible on the surface and the absence of the coating on the sample surface.

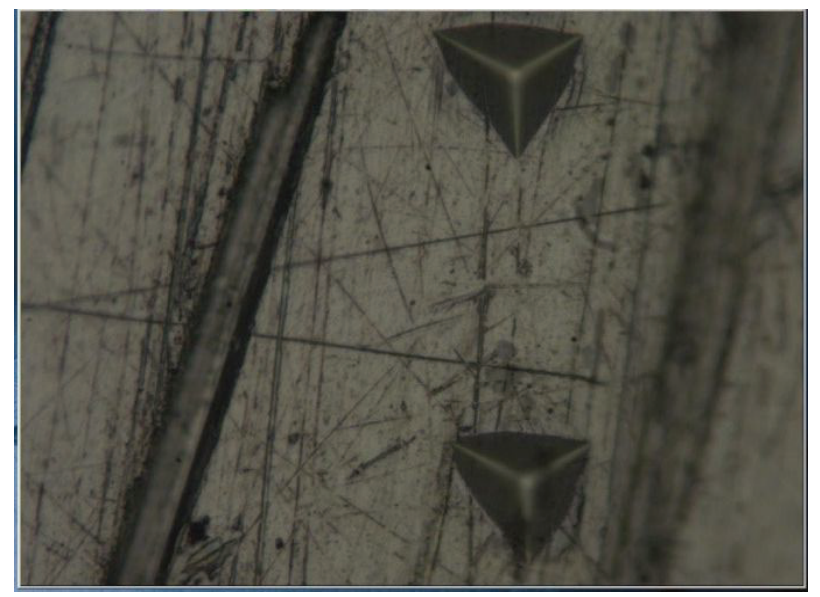

Fig. 2. Tridimensional SPM micro print image

On the fig. 3 there are shown curves of the loading and unloading and numerical indicators of the density of the initial surface.

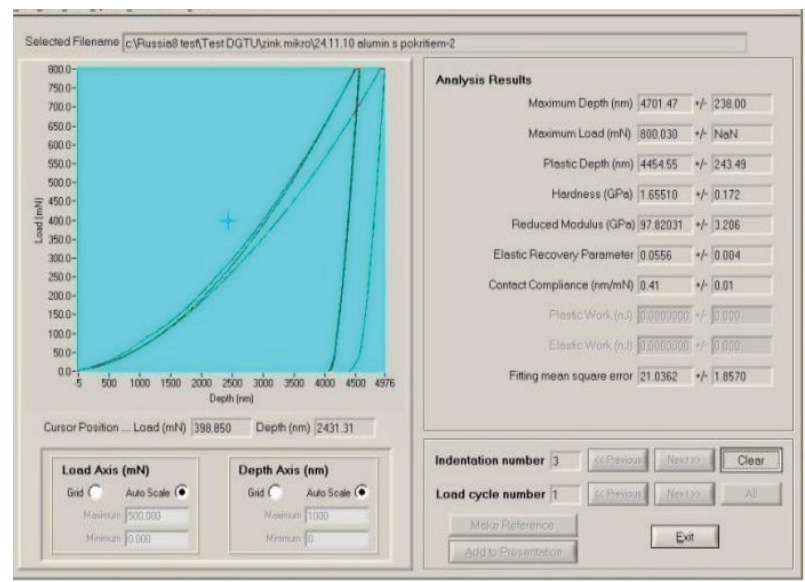

Fig. 3. The initial sample adenol aluminum. The square 500$1000 \mathrm{~nm}$.

Density $1.65 \mathrm{GPa}$. Curve of the «loading unloading» The time interval for VMCOL formation was 5, 10, $15 \mathrm{~min}$. All these factors created conditions for formation morphological oxide coating with different thickness.

After the coating within $5 \mathrm{~min}$ micro density increased up to the point $1,78 \mathrm{GPa}$ on the tridimensional
SPM image six micro prints, VMCOL in the initial stage of its formation is visible as light yellow parts of irregular shape (fig. 4).

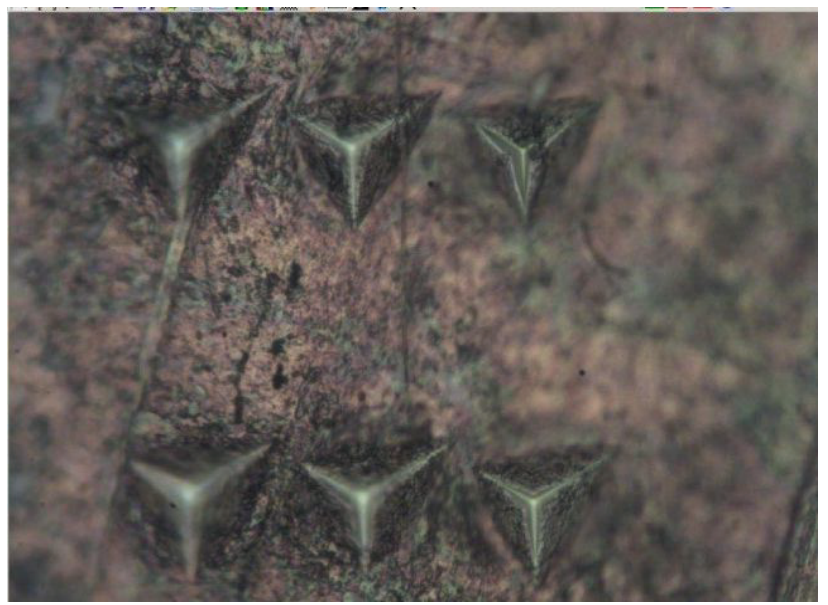

a)

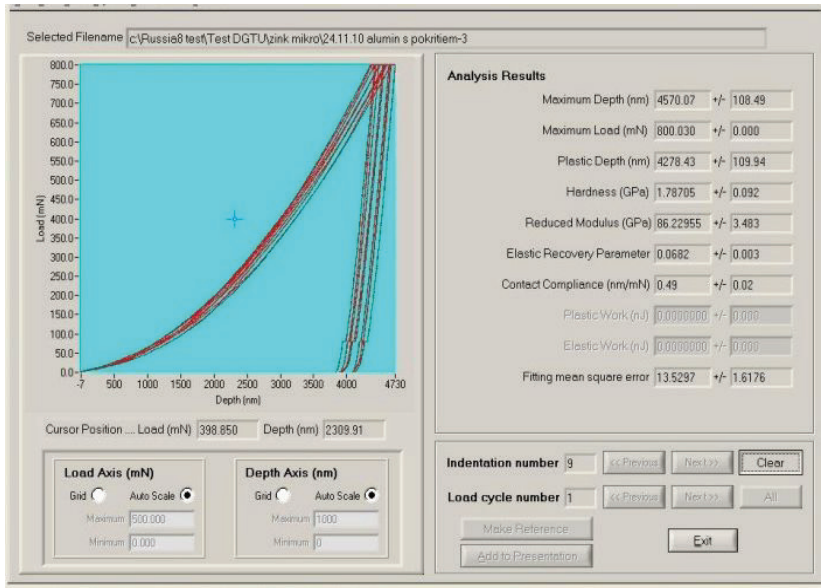

b)

Fig. 4. VMCOL top layer on the adenol aluminum alloy square 500-1000 nm; a $-\mathrm{T}=5 \mathrm{~min}$, density $1.78 \mathrm{GPa}$; $\mathrm{b}$ - tridimensional SPM image.

The increase time for oxide layer formation up to 10 min has lead to the increase of oxide layer thickness and accordingly micro density up to $2.03 \mathrm{GPa}$. (fig. $4 \mathrm{a}, \mathrm{b}$ )

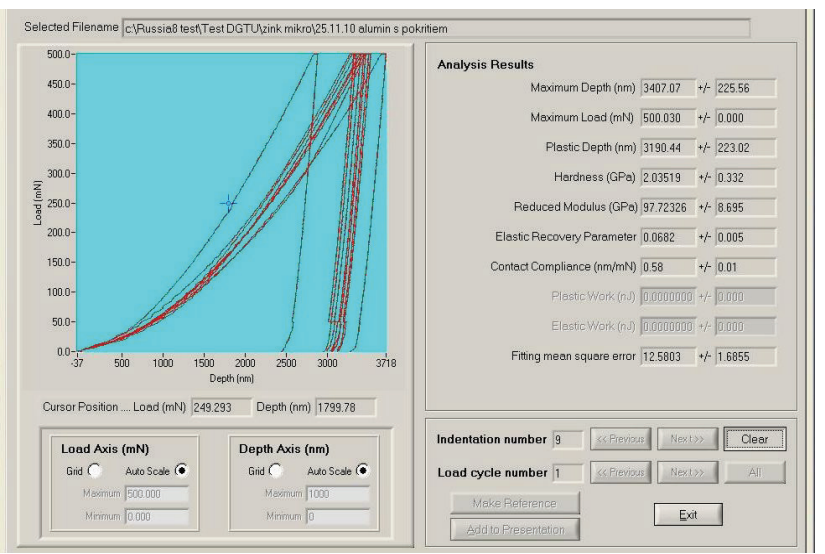

a) 


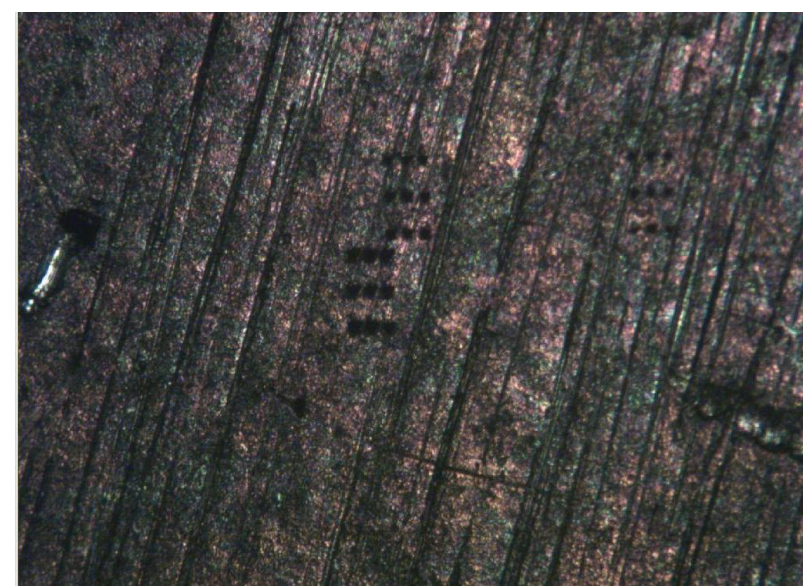

b)

Fig. 5. Top layer VMCOL on the adenol aluminum alloy square $500-1000 \mathrm{~nm}$; a $-\mathrm{T}=10 \mathrm{~min}$. density $2.03 \mathrm{GPa}$; $\mathrm{b}$ - tridimensional SPM image

As it's seen on the fig. 6 a,b the time increase up to $15 \mathrm{~min}$. has led to the formation of the layer with max thickness $5 \mathrm{mcm}$, density $2.18 \mathrm{GPa}$. on the aluminum surface.

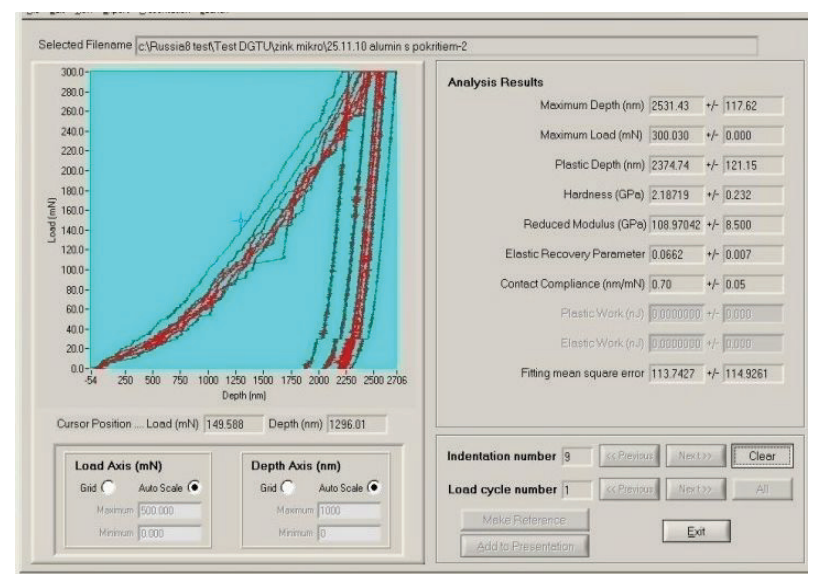

a)

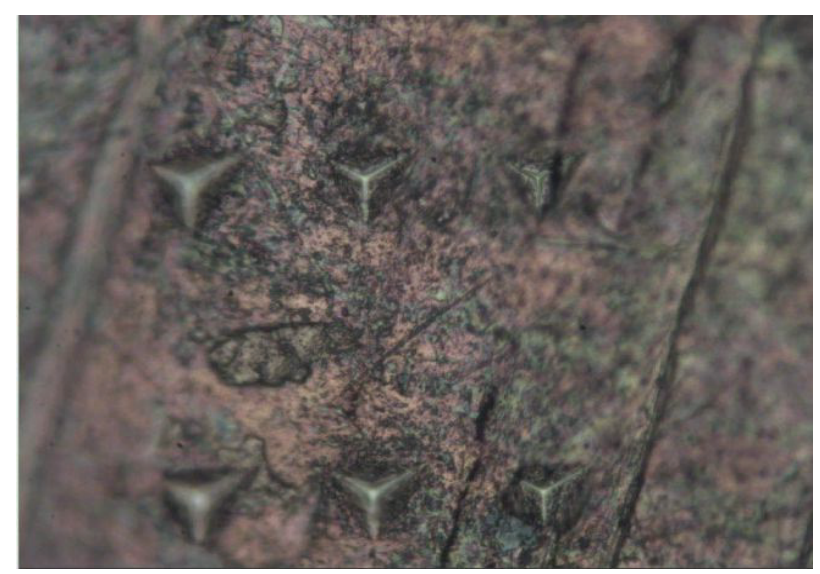

b)

Fig. 6. VMCOL top layer on the aluminum alloy square 500-1000 nm; a - T=15 min. density $2.18 \mathrm{GPa}$; $\mathrm{b}$ - tridimensional SPM image.
The analyses of the received results has shown that micro density VMCOL is $0,54 \mathrm{GPa}$ higher than initial sample (fig. 7), alongside with this maximal density of the top layer is $0,25 \mathrm{GPa}$ within the time period 5 and $15 \mathrm{~min}$. of the processing.

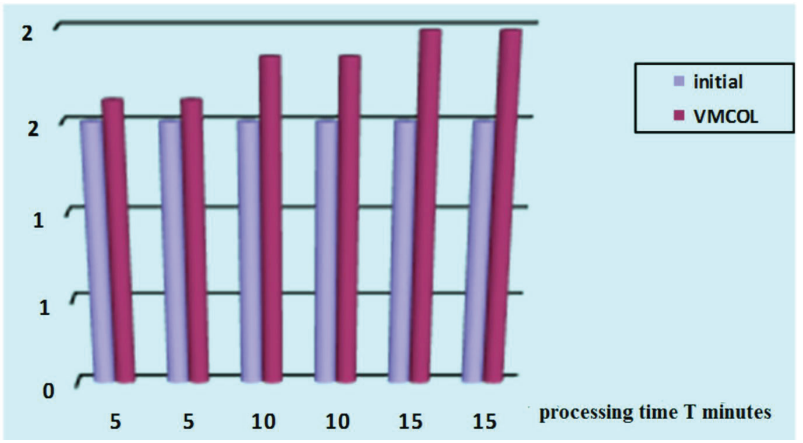

Fig. 7. Diagram of VMCOL density change

As the result of the carried out research the optimal technological process of placing of the vibrowave mechanical and chemical oxide coating has been defined, it consists of the following:

1. Loading of the details in the vibrowave camera.

2. Vibrowave mechanical and chemical oxide coating.

3. Washing down in the cold running water.

4. Washing down in the hot running water.

5. Unloading of the details.

6. Drying.

7. Final control.

\section{Conclusion}

Optimal regimes of the VMCOL have been specified. Swaying amplitude $-2,5 \mathrm{~mm}$. Swaying frequency -16 $\mathrm{Hz}$. Processing time $-15 \mathrm{~min}$. Working material is the polyethylene ball ø 2-2.5 mm. Layer thickness $5 \mathrm{mcm}$. density $2.18 \mathrm{GPa}$.

The research of the possibilities and usage of vibrowave mechanical and chemical oxide coating has shown, that protective and decorate coating placed on the details can be of different colors. Due to the increase layer density, protective capability is 1.5 times higher than oxide layer, received by the standard way.

\section{References}

1. A.P. Babichev, S.N. Shudaley Vibration Mechanical Chemistry in Processes of Finishing - Hardening Working and Coatings of Machinery (monograph) (DSTU Publishing House, Rostov-n/D, 2012)

2. V.V. Ivanov, Vibrowave mechanical and chemical oxide coating, 8, 8 p.p (2007)

3. J. Russell, Mechanical plaiting, (Book on Demand Ltd., 2013) ISBN13: 9785512398487

4. V.A. Lebedev, V.V. Ivanov, V.P. Fedorov Materials Science and Engineering, 124, 1-6, doi.10.1088/1757-899X/124/1/012160 (2016) 
5. V.V. Ivanov, E.V. Marchenko., S.V. Samurgashev, A.A. Sarabashev, Galvanic world, № 1 (32) (2016)

6. V.V. Ivanov, N.S. Dontsov, A.V. Kirichek, Key Engineering Materials, 736, 105-109, doi. 10.4028/www.scientific.net/KEM.736.105 (2017)

7. V.A. Lebedev, V.V. Ivanov, S.Y. Stine and I.V. Davydova, Uprochnyayushchiye tekhnologii i pokrytiya, 8, 19-23 (2015) 